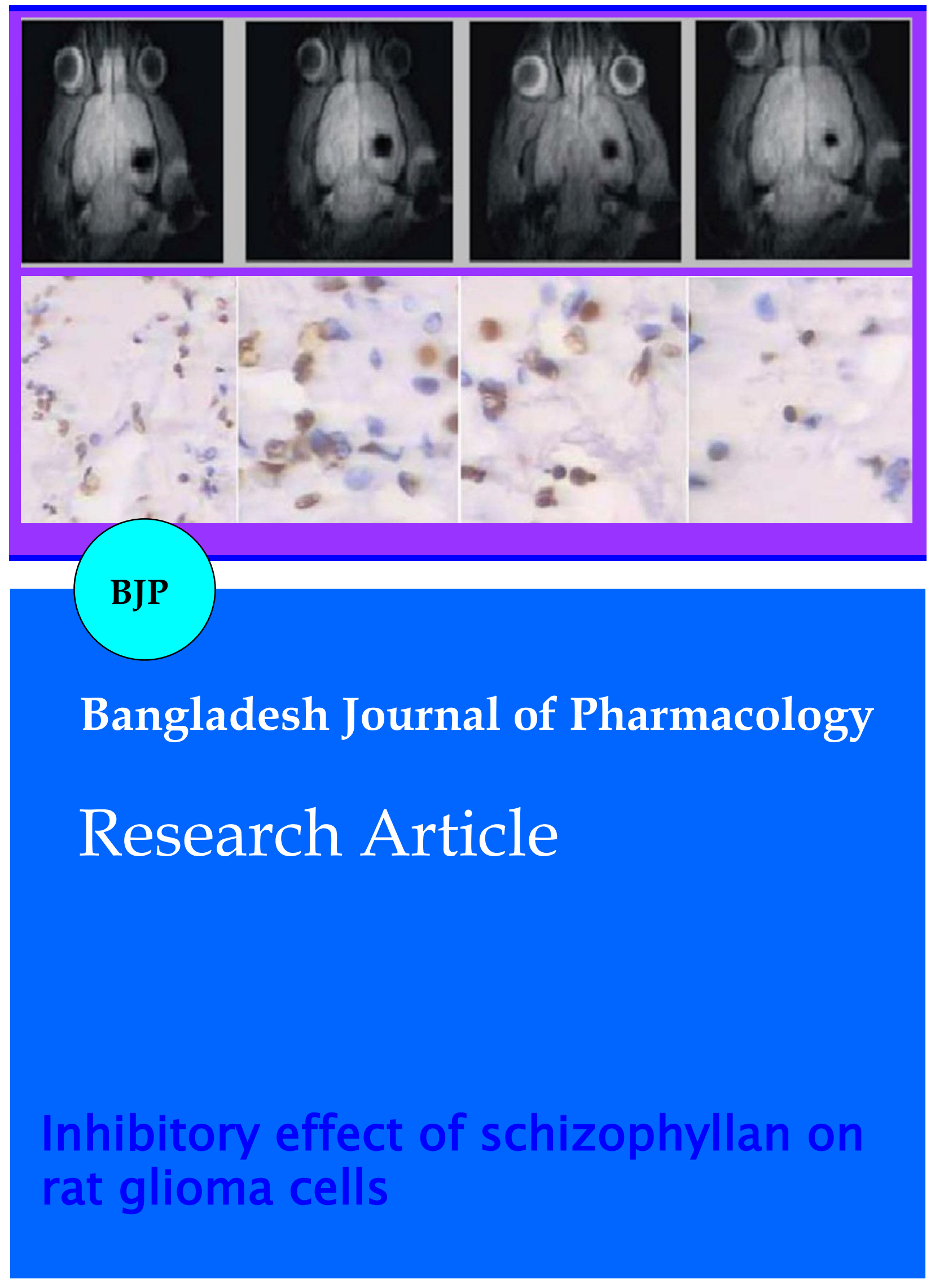




\title{
Inhibitory effect of schizophyllan on rat glioma cells
}

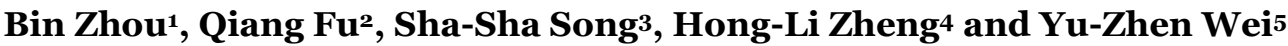 \\ ${ }^{1}$ Department of Neurosurgery, the Second Affiliated Hospital of Shandong University of Traditional Chinese \\ Medicine, Jinan 250001 , China; 'Department of Neurosurgery, Liaocheng People's Hospital, Liaocheng 252002, \\ China; ${ }^{3}$ Department of Pathology, Ji'nan Central Hospital Affiliated to Shandong University, Jinan 250 100, China; \\ ${ }^{4}$ Department of Neurosurgery, people's Hospital of Haiyang City, Haiyang 265 100, China; 5 Department of \\ Neurosurgery, Jining No.1 People's Hospital, Jining 272011 , China.
}

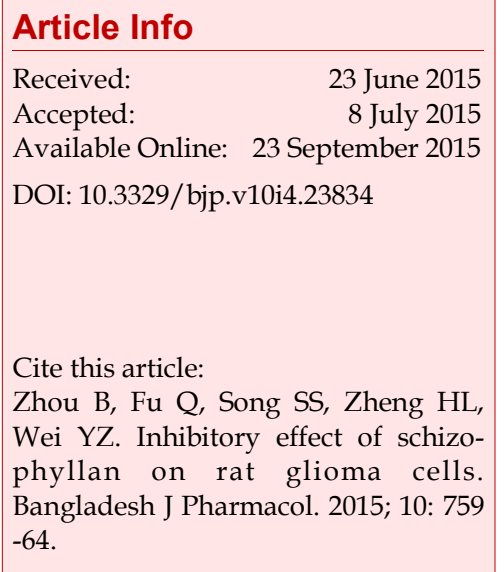

\begin{abstract}
The aim of this study was to examine the anticancer effects of schizophyllan (a -D-glucan) against the growth of rat CNS-1 glioma cells and preliminarily assess its effect on inducing apoptosis and blocking cell cycle. In order to evaluate its inhibitory effect, firstly MTT assay was conducted followed by annexin $\mathrm{V} /$ propidium iodide double staining or propidium iodide single staining, apoptosis and cell cycle using flow cytometry. All the experiments were carried in a dose- and time-dependent manner. Experimental results showed that treatment of 40 and $60 \mathrm{mg} / \mathrm{L}$ schizophyllan significantly increased the apoptotic rate and blocked the cell cycle. In addition, increase in the proportion of cells in G0/G1 phase and decrease in the proportion of S-phase cells were also observed. Overall experimental studies suggest that schizophyllan can significantly inhibit the growth of rat CNS-1 glioma cells, in vitro and induced apoptosis and blocked the cell cycle.
\end{abstract}

\section{Introduction}

Malignant gliomas account for approximately $50 \%$ of all central nervous system tumors (Mahaley et al., 1989; Avgeropoulos et al., 1994). Despite aggressive therapy attempts, mortality from malignant astrocytic gliomas, the most common intrinsic brain tumor in adult, still remains unacceptably high partly due to chemoresistance (Furnari et al., 2007). The highly lethal nature of this tumor partly originates from its invasive characteristics, which allow tumor cells to migrate and infiltrate eloquent areas making impossible the achievement of a radical surgery. Such invasive disease is, therefore, considered incurable using the treatment modalities presently available (Kislin et al., 2009). Therefore, the search for alternative preventive and therapeutic strategies continues to be an important goal.

Traditional herbal therapy treatment has been regarded as one promising alternative to modern medicine (Tan et al., 2011), and various investigations of active herbal components with antitumor or anti-invasive potential and fewer adverse effects than chemotherapeutic agents have been conducted (Meiyanto et al., 2012).

In general, medicinal mushrooms have been shown to improve cardiovascular health, stimulate immune function and contribute to glucose homoeostasis and to modulate detoxification, as well as exert anti allergic, antiviral, antibacterial, antifungal and anti-inflammatory activities (Martin et al., 2010). The bioactive polysaccharides isolated from mushroom fruit bodies, submerged cultured fungal biomass, or liquid culture fermentation broths are either $\beta$-D-glucans or $\beta$-Dglucan-protein complexes (proteoglycans) (Bohn and BeMiller, 1995).

A small number have progressed to clinical trials mainly in Japan and China such as lentinan (Lentinus edodes), schizophyllan (Schizophyllum commune), PSK and PSP (Trametes versicolor) and grifron-D (Grifora frondosa) (Sullivan et al., 2006). Schizophyllan, $(1 \rightarrow 3)-\beta-$ 
D-glucan, is a neutral polysaccharide produced by fungus Schizophyllum commune and consists of a $\beta-1,3-$ glucan main chain possessing a -1,6-glucoside sidechain at every third glucose unit (Figure 1). It is a soluble $(1 \rightarrow 3)-\beta$-D-glucan, used as a biological response modifier with radiation therapy for cancer treatment in Japan. $(1 \rightarrow 3)-\beta$-D-glucan is a group of immunomodulators, some of which have been used clinically. The mechanism of schizophyllan mediated antitumor activity is thought to be immune stimulation, which included cytokine production, hematopoietic response, modulation of cell surface antigen molecules essential for signal transduction, complement activation, antigen processing and presentation (Komatsuet al., 1969; Tsuchiyaet al., 1989; Tateishiet al., 1997; Hashimotoet al., 1997). Beta-glucan receptors might also contribute, at least in part, to the activity. The molecular mechanism of activity, however, has not yet been fully clarified. The administration of schizophyllan has been clinically found to prolong the survival of patients with advanced cervical cancer (Okamura et al., 1986) and with resectable gastric cancer (Furue, 1987). However, there have been no reports on the administration of schizophyllan for the glioma cancer and hence, we studied its inhibitory effects against the same.

\section{Materials and Methods}

\section{Materials}

Sprough-Dowley male rats $(n=45)$, with the body weights of $250 \mathrm{~g}$ were purchased from Shanghai SLAC Laboratory Animal Co., Ltd. CNS-1 rat glioma cells were purchased from Invitrogen ( $R$ \& D Systems, Minneapolis, USA). Schizophyllan was purchased from Sigma Chemical Co. (USA). DMEM medium and trypsin were bought from Nanjing Easeheal Pharmaceutical Co. Ltd. Fetal bovine serum, 3-(4,5-dimethylthiazol -2-yl)-2,5-diphenyltetrazolium bromide (MTT), annexin $\mathrm{V} /$ propidium iodide apoptosis detection kit and propidium iodide cell cycle assay kit were obtained from Santa Cruz Company (USA).

\section{Animal model establishment}

In this study, 5 rats were used for amplification. The CNS-1 glioma cell line was first expanded to $1 \times 10^{5} /$ $\mathrm{mL}$, and then was inoculated in the armpits and groins of the 5 rats, respectively. After tumor formation, the rats were killed by cervical vertebra dislocation to remove the tumors, in which necrotic tissues and blood clots were carefully removed and mixed with $0.9 \%$ sodium chloride solution to prepare tissue suspension for inoculation. The other 40 rats were injected intraperitoneally with $5 \%$ chloral hydrate $(200 \mathrm{mg} / \mathrm{kg})$, anesthetized and then fixed on stereotaxic apparatus. The hair near the anterior fontanelle was shaved, with routine disinfection. A hole was drilled with a dental drill 3-5 mm next to the right sagittal suture, with the diameter of $1.5 \mathrm{~mm}$. A microsyringe was vertically inserted into the site $3-5 \mathrm{~mm}$ under the cerebral duramater, and $100 \mu \mathrm{L}$ of tissue suspension was slowly injected into the right caudate nucleus of the rat, with the injection time longer than $3 \mathrm{~min}$. After the syringe needle was drawn, the bone hole was sealed with bone wax, and the skin was disinfected and sutured (Bidwell et al., 2013).

\section{Animal grouping}

40 rats were divided into 4 groups using random number table $(\mathrm{n}=10)$ : low-dose, schizophyllan group $(20 \mathrm{mg} / \mathrm{kg} /$ d), middle-dose, schizophyllan group $(40 \mathrm{mg} / \mathrm{kg} / \mathrm{d})$, high dose, schizophyllan group (60 mg/ $\mathrm{kg} / \mathrm{d})$ and control group. The 3 experiment groups were injected for a total of three treatment courses, seven days for a course and repeated after 1 day interval. The control group was intraperitoneally injected with $0.9 \%$ sodium chloride solution, similar to that of experiment groups.

\section{Tumor size}

In order to observe the changes in the tumor size, the head Gd-DTPA enhanced MRI examination was performed on the third week after CNS-1 cells implantation. In this study, the rat was fixed by ahead holder and determined the maximum tumor plane in coronal scan according to enhanced images. The measurement of maximum length and width of the tumor, as well as the maximum tumor plane in sagittal scan and height was also performed. The tumor inhibition rate was calculated according to these indices.

\section{Immunohistochemistry}

The rats were killed on the third week after treatment with schizophyllan. The tumor tissues were removed and made into $5 \mu \mathrm{m}$-thick paraffin sections by a conventional protocol. This is followed by the immunohistochemical staining to detect the morphological changes of glioma cells.

\section{Cell culture and MTT assay}

The cells were cultured in DMEM medium containing $5 \%$ fetal bovine serum, $100 \mathrm{U} / \mathrm{mL}$ penicillin, $100 \mu \mathrm{g} /$ $\mathrm{mL}$ streptomycin and $2 \mathrm{mM}$ L-glutamine and grown at $37^{\circ} \mathrm{C}$ under a humidified $5 \% \mathrm{CO}_{2}$ and $95 \%$ air at one atmosphere. For schizophyllan treatment, CNS-1 rat glioma cells were seeded at a density of approximately $1 \times 10^{5}$ cells $/ \mathrm{cm}^{2}$ in a well and allowed to adhere overnight. Schizophyllan was dissolved in DMSO prior to treatment. The concentration of DMSO in control experiments or in experimental samples was always $1 / 1000(\mathrm{v} / \mathrm{v})$ of the final medium volume. After 12 hours of pre-culture, schizophyllan was added, and the final concentrations were adjusted to 20,40 and $60 \mathrm{mg} /$ L respectively, and 24 hours, 48 hours or 72 hours after culture, each well was added $50 \mu \mathrm{L}$ of $1 \mathrm{~g} / \mathrm{L}$ MTT 
solution for another 12 hours of incubation. Then the liquid in each well was absorbed completely, and 100 $\mu \mathrm{L}$ of DMSO was added into each well and shaken for $20 \mathrm{~min}$ to fully dissolve the crystals. Absorbance were determined by spectrophotometer (Ultrospec 2100 Pro; Amersham Biosciences, Sweden) at $540 \mathrm{~nm}$. Cell viability was expressed as the absorbance ratio of the treatment to the control.

\section{Apoptosis and cell cycle}

To assess nuclear morphology, the nuclei of CNS-1 rat cells were stained with annexin $\mathrm{V} /$ propidium iodide. Cells were seeded onto 12-well microplates at $1 \times 10^{5}$ cells/well and were incubated with Schizophyllan at a concentration of 20,40 and $60 \mathrm{mg} / \mathrm{L}$ for 24 hours. After treatment, the cells were collected and fixed in $70 \%$ glacial acetic acid at $-20^{\circ} \mathrm{C}$ for 12 hours and then stained with annexin $\mathrm{V} /$ propidium iodide according to kit instructions to measure the cell cycle by a flow cytometry.

\section{Statistical analysis}

All data were expressed as mean \pm SE and analyzed by SPSS 15.0. The data were compared by one-way ANOVA, and $p<0.05$ was considered statistically significant.

\section{Results \\ Tumor growth}

The intracranial tumor in situ was successfully implantted, and conducted intensifying processing by MRI (Figure
1). These measurement results indicated that all the 3 schizophyllan treatment groups showed inhibited tumor growth, whereas the tumor growth in control group was found to be increased. The inhibition rates of the low-, medium- and high-dose schizophyllan groups were $(30.8 \pm 4.1) \%$, $(38.3 \pm 3.5) \%$ and $(55.3 \pm 5.1) \%$ respectively, indicating that schizophyllanis effective in glioma treatment.

\section{Immunohistochemistry}

The results confirmed that schizophyllan can inhibit the growth of CNS-1rat glioma (Figure 2). The results of antibody immunohistochemical staining showed that the tumor tissues in the schizophyllan treatment groups were flocculently scattered in brown, while those in the control group grew prosperously.

\section{Morphological changes and MTT assay}

Regarding the morphology, the number of glioma cells was significantly reduced and some cells even shrank and turned spherical 72 hours after administration with 20, 40 and $60 \mathrm{mg} / \mathrm{L}$ schizophyllan (Figure 3). The results of MTT assay showed that the CNS-1 cells activity was significantly found to be lowered 24,48 and 72 hours after treatment with 20, 40 and $60 \mathrm{mg} / \mathrm{L}$ schizophyllan,respectively $(\mathrm{p}<0.01)$ in a time- and concentration- dependent manner (Figure 4).

\section{Apoptosis and cell cycle}

The apoptosis results showed that after 24 hours, no obvious apoptosis and necrosis was found upon treatment with $20 \mathrm{mg} / \mathrm{L}$ of schizophyllan, whereas the

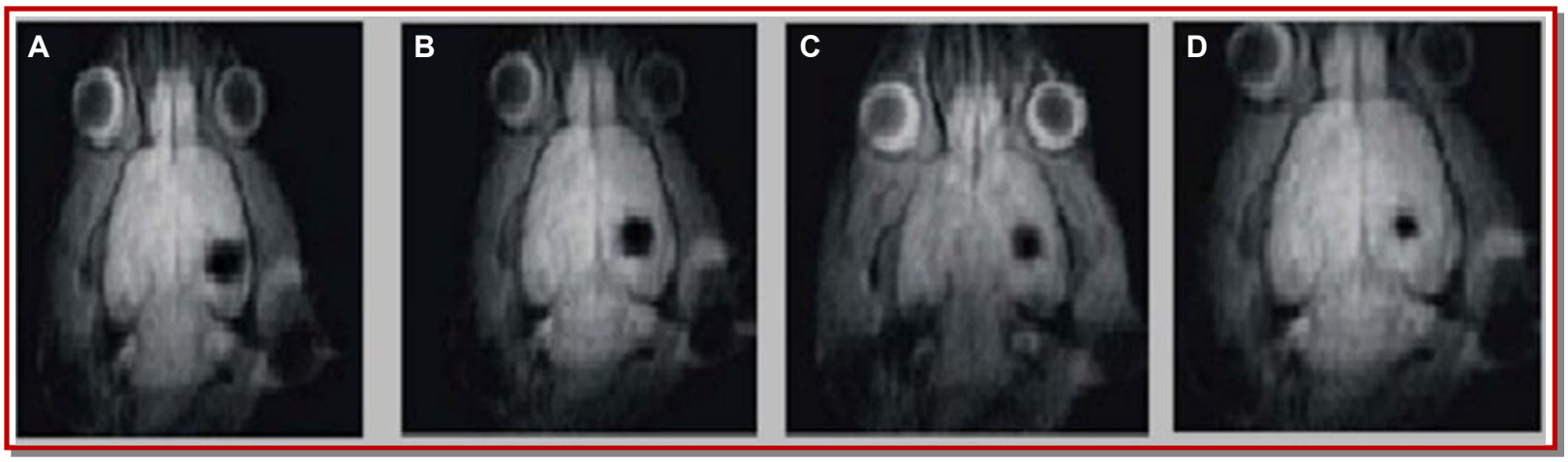

Figure 1: MRI results of intracranial tumors in situ. (A) control group; (B) low-dose group; (C) medium-dose group; (D) high-dose group

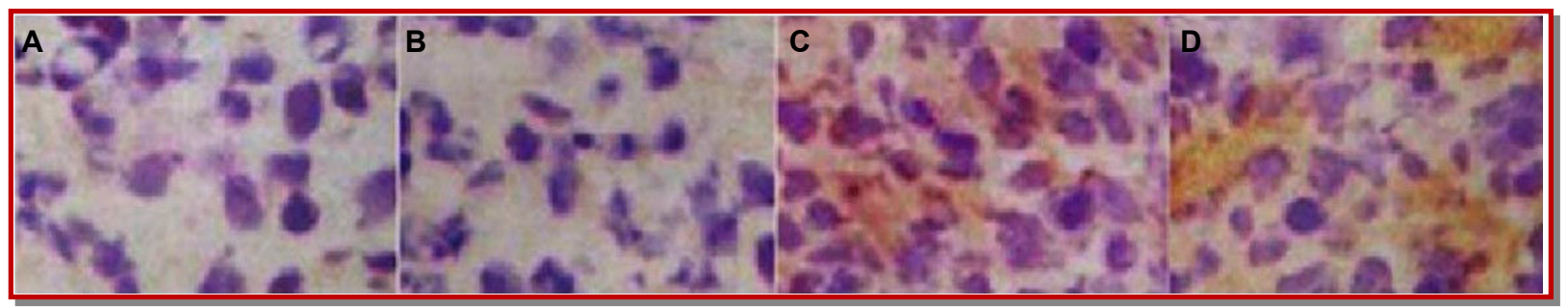

Figure 2: Immunohistochemical detection of tumor tissues. (A) control group; (B) low-dose group; (C) medium-dose group; (D) high-dose group 


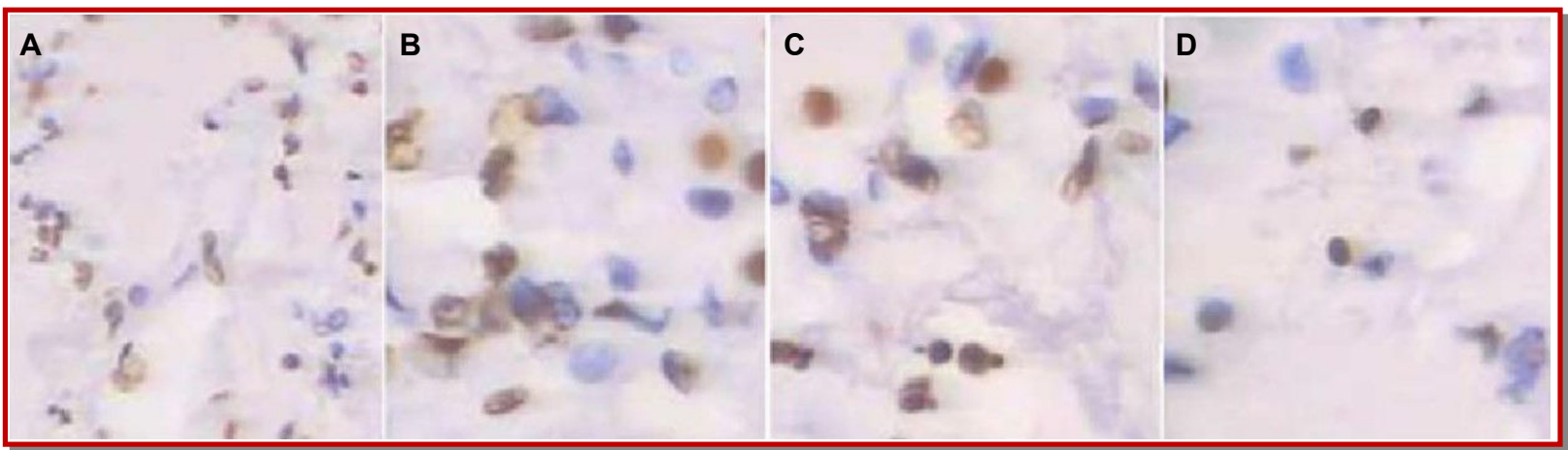

Figure 3: Schizophyllan effects on the morphology of CNS-1 cells. (A) control group; (B) low-dose group; (C) medium-dose group; (D) high-dose group

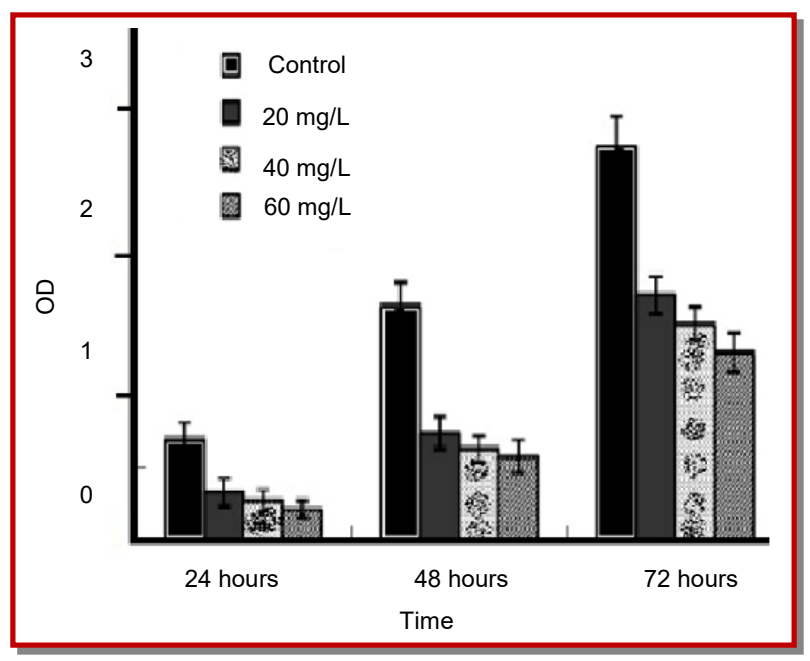

Figure 4: Schizophyllan effects on the MTT activity of CNS-1 cells

treatment with 40 and $60 \mathrm{mg} / \mathrm{L}$ schizophyllan significantly increased both the apoptosis and necrosis rates $(\mathrm{p}<0.01$, Figure 5). After 24 hours, the treatment of 20, 40 and $60 \mathrm{mg} / \mathrm{L}$ schizophyllan, the proportion of G0/ G1 phase cells was increased $(p<0.05)$, whereas that of $S$ -phase cells was significantly found to be decreased $(\mathrm{p}<0.01$, Figure 6).

\section{Discussion}

In this study, significantly schizophyllan inhibited the growth of rat CNS-1 glioma cells in vitro, of which 40 and $60 \mathrm{mg} / \mathrm{L}$ schizophyllan induced apoptosis, blocked cell cycle, markedly increased the proportion of cells in G0/G1 phase, and significantly lowered the proportion of S-phase cells. Considering the apoptosis results, this study showed that the apoptotic rate was markedly increased with the action of $40 \mathrm{mg} / \mathrm{L}$ schizophyllan for 24 hours. This may be due to the fact that the tumor cells have different types, leading to inconsistent drug effect or the drugs are not exactly or the methods for apoptosis detection are different. Propidium iodide single dye-labeled DNA
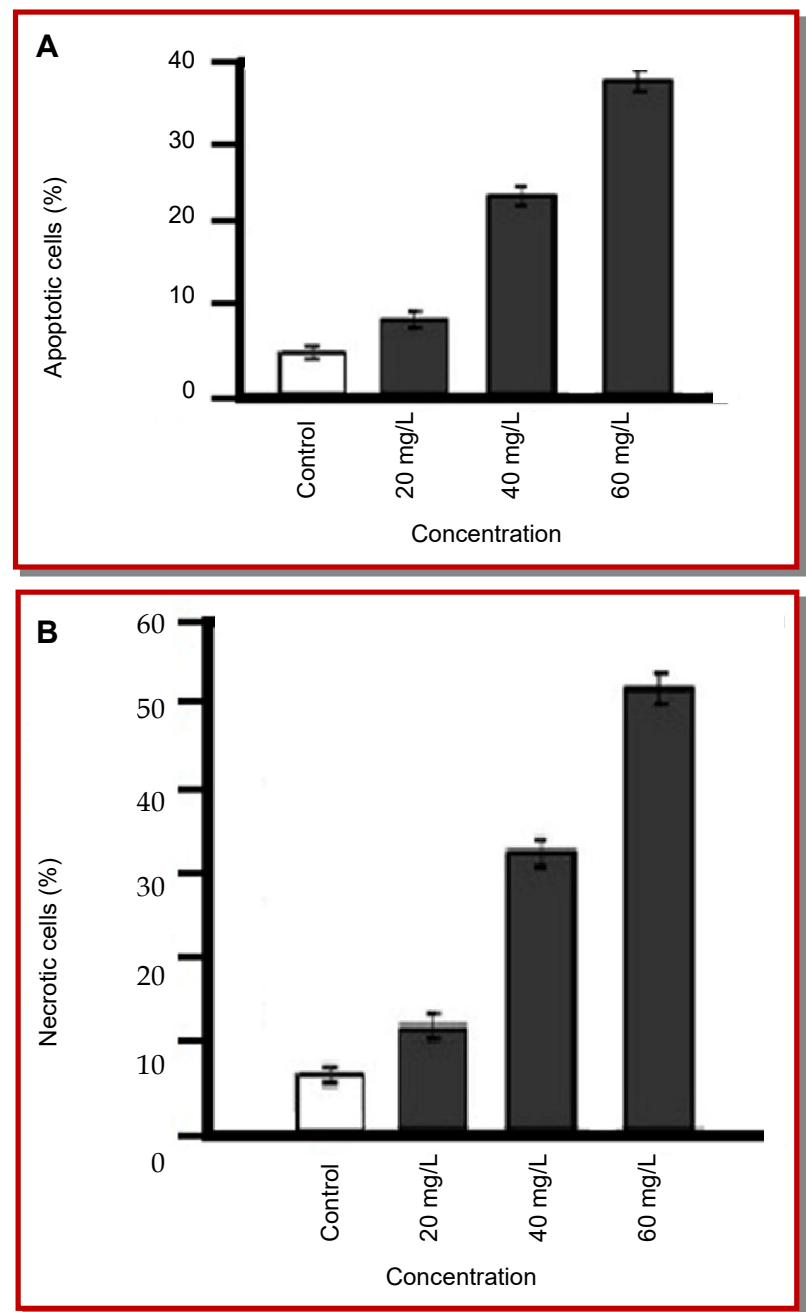

Figure 5: Schizophyllan effects on the apoptosis of CNS-1 cells

was used to detect apoptosis in the literatures related to this family molecules, while annexin V-propidium iodide double labeling was utilized in this study (Yoshino et al., 2010). Apoptotic rate can be calculated by counting the cell number of nuclear DNA. However, this detection may lead to a part of cells in early stage of apoptosis missed (Ina et al., 2012). In the early stage of 


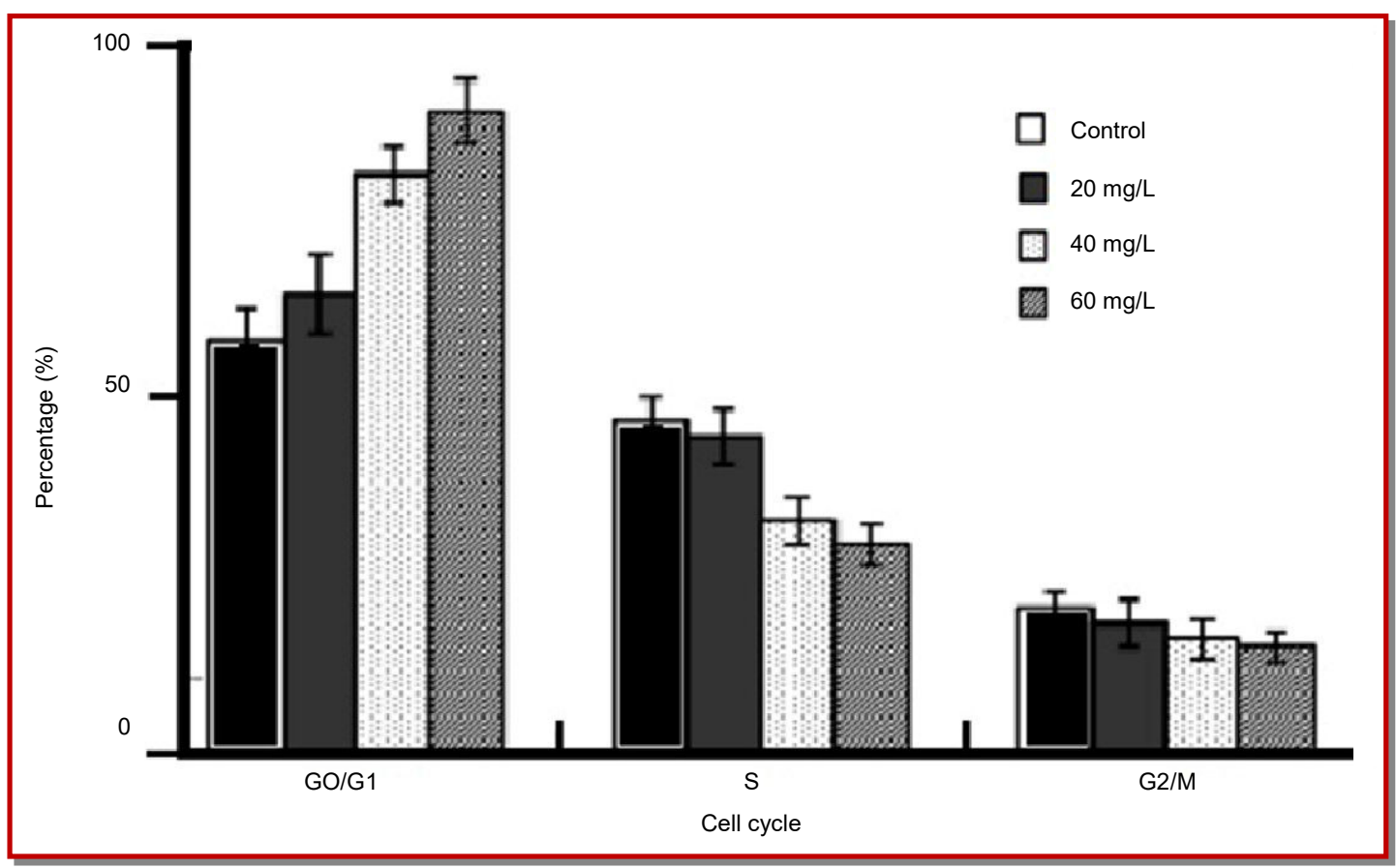

Figure 6: Schizophyllan effects on CNS-1 cell cycle

apoptosis, nuclear DNA fragmentation had not yet occurred, but the cell membrane had changed obviously. In other words, phosphatidylserine (PS) originally existed in the inner surface of cell membrane exposed to the outside of the membrane surface (Huang et al., 2012). Annexin V can quickly bind PS on the outer surface of membrane in the environment with calcium ions, so as to sensitively detect early apoptotic cells. Therefore, the annexin V-propidium iodide double labeling detection used herein is more sensitive and accurate (Hao et al., 2012).

\section{Conclusion}

We reported for the first time that schizophyllan with significant effect on inhibiting the growth of glioma cells cultured in vitro, which is correlated with the induction of apoptosis and cell cycle arrest, providing clues and evidence for the development of these drugs in the future.

\section{Acknowledgement}

We greatly acknowledged the Second Affiliated Hospital of Shandong University of Traditional Chinese Medicine, Liaocheng People's Hospital, Ji'nan Central Hospital Affiliated to Shandong University, People's Hospital of Haiyang City and Jining No. 1 People's Hospital for the financial support our research work.

\section{References}

Avgeropoulos NG, Batchelor TT. New treatment strategies for malignant gliomas. Oncologist 1994; 4: 209-24.
Bidwell GL 3rd, Perkins E, Hughes J, Khan M, James JR, Raucher D. Thermally targeted delivery of a c-Myc inhibitory polypeptide inhibits tumor progression and extends survival in a rat glioma model. PLoS One. 2013; 8: 104-07.

Bohn JA, BeMiller JN. (1-[3)-beta-D-glucans as biological response modifiers: A review of structure-functional activity relationships. Carbohydr Polym. 1995; 28: 3-14.

Borchers AT, Stern JS, Hackman RM, Keen CL, Gershwin ME: Mushrooms, tumors, and immunity. Proc Soc Exp Biol. Med. 1999; 221: 281-93.

Furnari FB, Fenton T, Bachoo RM, Mukasa A, Stommel JM, Stegh A, Hahn WC, Ligon KL, Louis DN, Brennan C, Chin L, DePinho RA, Cavenee WK. Malignant astrocytic glioma: Genetics, biology, and paths to treatment. Gene Dev. 2007; 21: 2683-710.

Furue H. Biological characteristics and clinical effort of sizofilan (SPG). Drugs Today. 1987; 23: 335-46.

Hao T, Wang YM, Li JJ, Du ZY, Duan CM, Wang CY, Song JP, Wang LJ, Li YH, Wang Y. Effect of lentinan against immunosuppression of lymphocytes cultured in simulated microgravity environment. Zhongguo Shi Yan Xue Ye Xue Za Zhi. 2012; 20: 182-86.

Hashimoto T, Ohno N, Yadomae T. Subgrouping immunomodulating $\beta$-glucans by monitoring IFN- $\gamma$ and NO syntheses. Drug Develop Res. 1997; 42: 35-40.

Huang X, Tu Z, Jiang Y, Xiao H, Zhang Q, Wang H. Dynamic high pressure microfluidization-assisted extraction and antioxidant activities of lentinan. Int J Biol Macromol. 2012; 51: 926-32.

Ina K, Kataoka T, Ando T. The use of lentinan for treating gastric cancer. Anticancer Agents Med Chem. 2012; 14: 15658.

Kimura Y, Tojima H, Fukase S, Takeda K. Clinical evaluation of sizofilan as assistant immunotherapy in treatment of head 
and neck cancer. Acta Otolaryngol Suppl. 1994; 511: 192-95.

Kislin KL, McDonough WS, Eschbacher JM, Armstrong BA, Berens ME. NHERF-1: Modulator of glioblastoma cell migration and invasion. Neoplasia 2009; 11: 377-87.

Komatsu N, Okubu S, Kikumoto S, Kimura K, Saito G. Hostmediated antitumour action of schizophyllan, a glucan produced by Schizophyllum commune. Gann 1969; 60: 137-44.

Mahaley MS, Mettlin C, Matarajan N, Laws ER, Peace BB. National survey of patterns of care for brain-tumor patients. J Neurosurg. 1989; 71: 826-36.

Martin KR, Brophy SK. Commonly consumed and specialty dietary mushrooms reduce cellular proliferation in MCF-7 human breast cancer cells. Exp Biol Med (Maywood). 2010; 235: 1306-14.

Meiyanto E, Hermawan A, Anindyajati. Natural products for cancer targeted therapy: Citrus flavonoids as potent chemopreventive agents. Asian Pac J Cancer Prev. 2012; 13: 427-36.

Okamura K, Suzuki M, Chihara T, Fujiwara A, Fukuda T, Goto S, Ichinohe K, Jimi S, Kasamatsu T, Kawai N, Mizuguchi K, Mori S, Nakano H, Noda K, Sekiba K, Suzuki K, Suzuki T, Takahashi K, Takeuchi K, Takeuchi S, Yajima A, Ogawa N.
Clinical evaluation of schizophyllan combined with irradiation in patients with cervical cancer: A randomized control study. Cancer 1986; 58: 865-72.

Sullivan R, Smith JE, Rowan NJ. Medicinal mushrooms and cancer therapy: Translating a traditional practice into Western medicine. Perspect Biol Med. 2006; 49: 159-70.

Tan W, Lu J, Huang M,Li Y, Chen M, Wu G, Gong J, Zhong $Z$, Xu Z, Dang Y,Guo J, Chen X, Wang Y. Anticancer natural products isolated from Chinese medicinal herbs. Chin Med. 2011; 6: 27.

Tateishi T, Ohno N, Adachi Y, Yadomae T. Increases in hematopoietic responses caused by JJ-glucans in mice. Biosci Biotech Biochem. 1997; 61: 1548-53.

Tsuchiya Y, Igarashi M, Inoue M, Kumagai K. Cytokinerelated immunomodulating activities of an anti-tumor glucan, sizofiran (SPG). J Pharmacobiodyn. 1989; 12: 616-25.

Yoshino S, Watanabe S, Imano M, Suga T, Nakazawa S, Hazama S, Oka M. Improvement of QOL and prognosis by treatment of superfine dispersed lentinan in patients with advanced gastric cancer. Hepatogastroenterology 2010; 57: 172-77. 